\title{
Ozone effects on photosynthesis of ornamental species suitable for urban green spaces of China
}

\author{
Ning Yang ${ }^{\mathrm{a}, \mathrm{b}}$, Xiaoke Wang ${ }^{\mathrm{a}}$, Lorenzo Cotrozzi ${ }^{\mathrm{c}}$, Yuanyuan Chen ${ }^{\mathrm{a}, \mathrm{b}}$, Feixiang Zheng ${ }^{\mathrm{a}, \mathrm{d}, *}$ \\ a State Key Laboratory of Urban and Region Ecology, Research Center for Eco-Environmental Sciences, Chinese Academy of Sciences, Beijing 100085, China \\ ${ }^{\mathrm{b}}$ University of Chinese Academy of Sciences, Beijing 100049, China \\ c Department of Agriculture, Food and Environment, University of Pisa, Via del Borghetto, 8056124 Pisa, Italy \\ ${ }^{\mathrm{d}}$ Institute of Environment and Sustainable Development in Agriculture, Chinese Academy of Agricultural Sciences, Beijing 100081, China
}

\section{A R T I C L E I N F O}

\section{Article history:}

Received 14 May 2016

Received in revised form 27 October 2016

Accepted 27 October 2016

Available online 27 October 2016

\section{Keywords:}

Biometric parameters

Marigold

$\mathrm{O}_{3}$

Photosynthetic performance

Rose

Smoke tree

\begin{abstract}
A B S T R A C T
Urban green spaces (UGS) offer several ecosystemical benefits to the urban environment. However, these advantages may be weakened by alterations of plants photophysiological mechanisms due to increasing tropospheric ozone $\left(\mathrm{O}_{3}\right)$ concentrations, a serious problem for China. To evaluate their utilization in UGS, we selected three widely-used urban plant species (smoke tree, Cotinus coggygria Scop.; marigold, Tagetes erecta Linn.; rose, Rosa chinensis Jacp.) to investigate their biometric and photophysiological responses to (i) ambient air (AA), (ii) $A A+60 \mathrm{ppb} \mathrm{O}_{3}(\mathrm{AA}+60)$, and (iii) $\mathrm{AA}+120 \mathrm{ppb} \mathrm{O} 3(\mathrm{AA}+120)\left(9 \mathrm{~h} \mathrm{~d}^{-1}\right.$, from $8: 30$ am to $5: 30 \mathrm{pm})$. Considering visible injury and biomass production, smoke tree and marigold seem to be $\mathrm{O}_{3}$-sensitive, whereas rose should be considered more tolerant. The exposure to the pollutant gas reduced photosynthetic efficiency in all seedlings. However, different features were shown throughout our study by the three species here monitored. In smoke tree, stomatal limitations seemed to be its principal weakness. In marigold, the reduction of the photosynthetic performance was mainly ascribable to impairments of both light and dark reactions of photosynthesis. Here, stomatal closure maybe not the cause to limit the photosynthetic rate, but a down-regulated response. Unexpectedly, $\mathrm{CO}_{2}$ assimilation increased in roses exposed to $A A+60$ and did not change in those treated with $A A+120$ after one month from the beginning of the exposure (FBE). This seemed due to a better efficacy of these plants in dark reactions of photosynthesis. This feature was confirmed also a month later. In conclusion, the results of this study indicate that non-invasive methods such as gas exchange and chlorophyll fluorescence for monitoring photosynthetic performance of urban plants can be useful to give guidelines to manage UGS in the "climate change era". Generally, in severe $\mathrm{O}_{3}$-polluted areas as those of several cities of China, the plants with high-efficient biochemical processes driving a well photosynthetic performance (such as rose) might be a recommended choice.
\end{abstract}

C 2016 Elsevier GmbH. All rights reserved.
Abbreviations: $\mathrm{A}_{\text {sat }}$, light-saturated photosynthesis; $\mathrm{C}_{\mathrm{i}}$, intercellular $\mathrm{CO}_{2}$ concentration; \%D, fraction of absorbed light thermally dissipated in PSII antennae; FBE, from the beginning of the exposure; $F_{v}$ '/Fm', actual photochemical efficiency of PSII in the saturated light; $g_{s}$, stomatal conductance; $J_{\max }$, light-satured rate of electron transport; Ls, stomatal limitation to photosynthesis; M9, the daily 9-h mean $\mathrm{O}_{3}$ concentration; $\mathrm{NO}_{\mathrm{x}}$, nitrogen oxides; OTC, open-top chamber; \%P, fraction of absorbed light utilized in PSII photochemistry; $\Phi_{\mathrm{PSII}}$, light-adapted apparent quantum efficiency of PSII; PPFD, photosynthetic photon flux density; PSII, photosystem II; qP, photochemical quenching; $\mathrm{RH}$, relative humidity; RuBP, 1,5-diphosphate ribulose; TPU, triose phosphate utilization; UGS, urban green spaces; $\mathrm{V}_{\mathrm{cmax}}$, maximum rate of Rubisco-limited carboxylation; VOCs, volatile organic compounds; \%X, fraction of light absorbed by PSI neither used in photochemistry nor dissipated in the PSII antenna.

* Corresponding author.

E-mail address: zhengfeixiang@caas.cn (F. Zheng).

\section{Introduction}

Urban green spaces (UGS) offer several ecosystemical benefits to the urban environment, not only in relation to their aesthetic and social values but also for their effects on air quality (Pellegrini, 2014). Plants can beautify cities, improve eco-environment, promote living in harmony between human and nature, and contribute to public health, aesthetic enjoyment and physical and psychological well-being (Jo, 2002; Chen and Jim, 2008), suggesting their irreplaceable roles during urbanization. However, these advantages provided by UGS may be weakened by alterations of plants photophysiological mechanisms due to increasing tropospheric ozone $\left(\mathrm{O}_{3}\right)$ concentrations. Currently, $\mathrm{O}_{3}$ has been proved to be one of the most toxic gaseous substances that significantly impacts plant life (Cotrozzi et al., 2016; Yi et al., 2016). 
The fast economic development of China is producing serious air pollution problems. Large quantities of nitrogen oxides $\left(\mathrm{NO}_{\mathrm{x}}\right)$ and volatile organic compounds (VOCs) are emitted from massive fossil fuel combustion of industrial activities and vehicular traffic. This phenomenon contributes to increasing ambient $\mathrm{O}_{3}$ concentrations, especially in the regions with dense population, such as Beijing, Shanghai, and Guangzhou areas (Li et al., 2013; Zheng et al., 2014). Taking Beijing as an example, the daily mean (24-h) and hourly peak $\mathrm{O}_{3}$ concentrations at urban and exurban regions were 46 and 67 ppb, and 181 and 209 ppb, respectively, during May-September 2010 (Feng et al., 2014) (for $\mathrm{O}_{3}, 1 \mathrm{ppb}=1.96 \mu \mathrm{g} \mathrm{m}^{-3}$, at $25^{\circ} \mathrm{C}$ and $101.325 \mathrm{kPa}$ ). This confirms the well-known phenomenon of long range transport of $\mathrm{O}_{3}$ precursors from urban to exurban areas, often leading to higher levels of the pollutant in regions far from cities or industrial zones (Lorenzini et al., 1995). Evenmore, the daily mean (24-h) $\mathrm{O}_{3}$ concentration in May-September 2014 reached $71.3 \mathrm{ppb}$ in exurban regions (Yuan et al., 2015). Thus, $\mathrm{O}_{3}$ pollution has not been effectively controlled in recent years, and UGS are still living under high $\mathrm{O}_{3}$ concentrations, expected to induce serious damages to plants.

Analysis and monitoring of plant responses to urban conditions, defined as "urban plant physiology" (Calfapietra et al., 2015) or "urban plant pathology" (Lorenzini and Nali, 2015), has been identified as a critical component of research programs. It represents an important opportunity to gain immediately an insight in relation to the physiological responses and the mechanisms (type and extent) of plant acclimation/tolerance. Current knowledge of plant photophysiology in the urban environment is mainly based on two non-destructive methodological approaches: (i) gas exchange analysis, and (ii) chlorophyll $a$ fluorescence measurement.

Photosynthesis is the foundation of material cycle and energy conversion of plant, and is the primary carbon source for biomass formation. It is influenced by multiple step processes involving (i) carbon dioxide $\left(\mathrm{CO}_{2}\right)$ diffusion from atmosphere to leaf through stomata, (ii) light energy utilization and conversion (light reactions), and (iii) ribulose-1,5 biphosphate carboxylase/oxygenase (RuBisCo) carboxylation (dark reactions). Inhibition of any of these steps may affect the photosynthetic performance. Several experimental studies showed that $\mathrm{O}_{3}$ stress induced decline in photosynthesis in parallel with decrease in stomatal conductance, while the intercellular $\mathrm{CO}_{2}$ concentration remained constant or even increased, suggesting that stomatal closure may be only a downward-regulation response to decreased photosynthesis rather than the cause (Watanabe et al., 2014). Furthermore, several authors documented that the direct effect of $\mathrm{O}_{3}$ on light and dark phases of photosynthesis was the main cause of its decline (e.g. Power and Ashmore, 2002). The detrimental effects of $\mathrm{O}_{3}$ on potential photosystem II (PSII) photochemical efficiency $\left(\mathrm{F}_{\mathrm{v}} / \mathrm{F}_{\mathrm{m}}\right)$, actual photochemical efficiency of PSII in the saturated light $\left(\mathrm{F}_{\mathrm{v}}{ }^{\prime} / \mathrm{F}_{\mathrm{m}}{ }^{\prime}\right)$, light-adapted apparent quantum efficiency of PSII ( $\left.\Phi_{\text {PSII }}\right)$ and the percentage of open photosynthetic reaction centers $(\mathrm{qP})$ have been widely reported (e.g. Feng et al., 2011b; Pellegrini, 2014; Zhang et al., 2014), suggesting that photochemistry was depressed and the production of NADPH and ATP for $\mathrm{CO}_{2}$ reduction may be decreased. A reduction of maximum rate of RuBisCo-limited carboxylation $\left(\mathrm{V}_{\mathrm{cmax}}\right)$ has also been considered a main factor being responsible for impairment of photosynthesis (Matyssek et al., 1991; Zheng et al., 2002; Morgan et al., 2004; Fiscus et al., 2005; Pellegrini et al., 2011). These are interesting findings to select and breed $\mathrm{O}_{3}$-tolerant species, but so far the photosynthetic mechanisms, including stomatal change, and light and dark reaction responses have not been explored enough.

Biomass production is to some extent the comprehensive reflection of photosynthetic capacity. Studies over the past several decades indicated that chronic $\mathrm{O}_{3}$ exposure significantly decreased the production of forests (Proietti et al., 2016), crops (Avnery et al., 2011; Ghude et al., 2014; Chuwah et al., 2015) and grasslands (Gilliland et al., 2016). However, there are some exceptions where $\mathrm{O}_{3}$ exposure promoted biomass accumulation under particular environmental conditions (e.g. Prozherina et al., 2003). That photophysiological mechanisms lead to reverse biomass production responses to $\mathrm{O}_{3}$ stress among different plant species has rarely been systematically explored.

Smoke tree (Cotinus coggygria Scop.), marigold (Tagetes erecta Linn.) and rose (Rosa chinensis Jacp.) have been widely used in urban landscaping (e.g. smoke tree contributed to 71\% of Red Leaves, the most spectacular natural scenery in Fragrant Hills Park, an imperial garden in the northwestern part of Beijing), introduced in residential areas, parks, squares or on sides of roads. They are representative greening and ornamental plant species in cities. Before experiment, we consulted previous literatures to understand how these three species adapt to rising $\mathrm{O}_{3}$ concentration through regulating photosynthetic mechanism. However, to the best of our knowledge, no study has been performed on this crucial topic. Only few reports on the photosynthetic efficiency responses of these species to other abiotic stresses were achieved (drought and high temperatures; van Iersel and Seymour, 2002; Li et al., 2011; Riaz et al., 2013) and, by the way, only the final photosynthetic rate was exhibited. Thus, we conducted this experiment to investigate the $\mathrm{O}_{3}$ sensitivity (based on biomass production) of these three plant species, and to explore their crucial photophysiological mechanisms resulting in different biomass responses to elevated $\mathrm{O}_{3}$ by analyzing stomatal factor along with photochemical and biochemical processes of photosynthesis in order to evaluate their utilization in UGS.

\section{Materials and methods}

\subsection{Plant material and ozone exposure}

Experiments were conducted at Zhangtou village $\left(40^{\circ} 12^{\prime} \mathrm{N}\right.$, $\left.116^{\circ} 8^{\prime} \mathrm{E}\right)$, Changping District, Beijing, China, where in 2013 and 2014 (the experimental period) the average annual temperature and precipitation were $12.1^{\circ} \mathrm{C}$ and $542 \mathrm{~mm}$ (concentrated from June to August), respectively (Chen et al., 2016).

Seedlings were purchased from a local farmer (smoke trees were one-year old, whereas rose and marigold were just emerged in the current year when relative experiments were conducted), and individually planted into plastic pots $(17 \mathrm{~cm}$ in height and $22 \mathrm{~cm}$ in diameter) filled with native soil. About 10 days later, when plants were adapted to pots conditions, 30 seedlings of smoke tree and 60 of rose and marigold, each, with similar height $(102,24$ and $7 \mathrm{~cm}$ for smoke tree, rose and marigold, respectively) and stem diameter (12.5, 8 and $4 \mathrm{~mm}$, respectively) were selected and equally distributed to three octagonal open top chambers (OTCs; $2.8 \mathrm{~m}$ in height and $4.0 \mathrm{~m}$ in diameter), made of aluminum alloy frame covered with stalinite; (Zheng et al., 2011). Three treatments were applied (one for each OTC): (i) ambient air (AA), (ii) AA with the addition of $60 \mathrm{ppb} \mathrm{O}_{3}(\mathrm{AA}+60)$, and (iii) AA with the addition of $120 \mathrm{ppb} \mathrm{O}_{3}\left(\mathrm{AA}+120\right.$ ) (for $\mathrm{O}_{3}, 1 \mathrm{ppb}=1.96 \mu \mathrm{g} \mathrm{m}^{-3}$, at $25^{\circ} \mathrm{C}$ and $101.325 \mathrm{kPa}) . \mathrm{O}_{3}$ was generated from pure oxygen by an $\mathrm{O}_{3}$ generator (HY003, Chuangcheng Co., Jinan, China) using a high voltage discharge method (Zheng et al., 2013), and then mixed with AA to achieve the target concentration. Depending on the growth season of each species, smoke tree, rose and marigold seedlings were exposed to $\mathrm{O}_{3}\left(9 \mathrm{~h} \mathrm{~d}^{-1}\right.$, from 8:30 am to 5:30 pm) from 23 June to 19 October 2013 (118 days), 23 June to 29 October 2013 (128 days), and 5 August to 28 September 2014 (54 days), respectively (with exception of rainy and windy days). During exposure period, the average temperature, relative humidity (RH) and precipitation were $24.3^{\circ} \mathrm{C}$, $77.3 \%$ and $365.2 \mathrm{~mm}$ for smoke tree and rose, respectively, and 
$24.2{ }^{\circ} \mathrm{C}, 77.0 \%$ and $36.1 \mathrm{~mm}$ for marigold. To attenuate positional effects, pots were re-positioned within the OTCs every 7 days, and re-distributed among OTCs every $10-15$ days (as described by Feng et al., 2011a). $\mathrm{O}_{3}$ concentration into each OTC was continually measured and automatically stored by an $\mathrm{O}_{3}$ analyzer (Model 49i, Thermo Scientific, Franlin, MA, USA). The percentage of actual to target increment was from $-3.9 \%$ to $+17.4 \%$ during $\mathrm{O}_{3}$ exposure, which basically achieved the target concentration. Temperature and $\mathrm{RH}$ within two OTCs during $\mathrm{O}_{3}$ exposure were measured every 5 min using a weather station (Campbell Scientific, North Logan, Utah, USA; Fig. S1 in appendix): the average temperatures for smoke tree, rose and marigold within the two chambers were 24.2 and $24.3^{\circ} \mathrm{C}, 22.9$ and $23.0^{\circ} \mathrm{C}$, and 23.9 and $24.2^{\circ} \mathrm{C}$; the averages for $\mathrm{RH}$ were 77.0 and $77.3 \%, 76.0$ and $76.2 \%, 78.1$ and $77.0 \%$. This data confirms that there were similar micro-meteorological conditions among OTCs. The plants were irrigated enough with running water after 5:30 pm every day (after $\mathrm{O}_{3}$ fumigation); and visible foliar injury was checked on each plant, in order to detect its time of onset.

\subsection{Ecophysiological analyses}

For each species, five plants were randomly collected from each OTC, and one fully expanded leaf for each plant was selected and marked for ecophysiological analyses, which were taken on two measuring times: on 23 July ( 30 days from the beginning of exposure, FBE) and 23 August (60 days FBE) 2013 for both smoke tree and rose, and on 22 August (17 days FBE) and 6 September 2014 (32 days FBE) for marigold. For smoke tree and rose, the AOT40 (Accumulated $\mathrm{O}_{3}$ exposures Over a Threshold of $40 \mathrm{ppb}, 08.00$ a.m. -08.00 p.m.; sensu de Leew and van Zantwoort, 1997) at the first and second measuring times were 4.0 and 6.6, 15.0 and 24.7 and 24.1 and $41.4 \mathrm{ppm}$ h in AA, AA+60 and AA+120 OTCs, respectively. For marigold, they were 5.8 and 9.7, 15.4 and 26.5, 24.6 and $43.0 \mathrm{ppm}$ h.

Gas exchange and chlorophyll $a$ fluorescence measurements were conducted using a LI-6400 photosynthesis system with a leaf chamber fluorometer (LI-COR, Lincoln, NE, USA). The automatic program of the LI-6400 photosynthesis system was used to generate the response of $\mathrm{CO}_{2}$ assimilation rate $(\mathrm{A})$ to photosynthetic photon flux density (PPFD), according to Gomes et al. (2006) with some minor modifications: measurements were taken following a gradient of PPFD $(1500,1200,900,600,250,150,75,0 \mu \mathrm{mol}$ photons $\mathrm{m}^{-2} \mathrm{~s}^{-1}$ ) under a constant $\mathrm{CO}_{2}$ concentration of $400 \mathrm{ppm}$ and a block temperature of $25^{\circ} \mathrm{C}$. A/PPFD curves were fitted by the "Photosynthesis Work-Bench" software and were used to obtain light-saturated photosynthesis $\left(\mathrm{A}_{\mathrm{sat}}\right)$, and corresponding stomatal conductance $\left(\mathrm{g}_{\mathrm{s}}\right)$ and intercellular $\mathrm{CO}_{2}$ concentration $\left(\mathrm{C}_{\mathrm{i}}\right)$ at the PPFD of $1200 \mu \mathrm{mol} \mathrm{m}^{-2} \mathrm{~s}^{-1}$.

The automatic program in the LI-6400 photosynthesis system was also used to generate $A / C_{i}$ curves, according to Feng et al. (2011b) with some minor modifications: measurements were taken by changing the $\mathrm{CO}_{2}$ concentration $(400,300,20$, $10,50,400,575,800,1000,1200,1500 \mathrm{ppm}$ ) under a constant PPFD of $1200 \mu \mathrm{mol} \mathrm{m}^{-2} \mathrm{~s}^{-1}$ and a block temperature of $25^{\circ} \mathrm{C}$. Then, $\mathrm{V}_{\mathrm{cmax}}$, light-saturated rate of electron transport $\left(\mathrm{J}_{\max }\right)$ and triose phosphate utilization (TPU) were calculated from the $A / C_{i}$ curves generated from the "Photosynthesis Work-Bench" software. Actual photochemical efficiency of PSII in the saturated light $\left(\mathrm{F}_{\mathrm{v}}{ }^{\prime} / \mathrm{F}_{\mathrm{m}}{ }^{\prime}, \mathrm{qP}\right.$ and $\left.\Phi_{\text {PSII }}\right)$ were extracted from the measurements at $400 \mathrm{ppm}$ of $\mathrm{CO}_{2}$. The distribution of light energy absorbed by PSII was calculated according to Demmig-Adams et al. (1996): fraction of light absorbed by PSII antenna that is thermally-dissipated $(\% \mathrm{D})=1-\left(\mathrm{F}_{\mathrm{v}}{ }^{\prime} / \mathrm{F}_{\mathrm{m}}{ }^{\prime}\right) \times 100$, fraction of light absorbed by PSII antenna that is used in photochemistry $(\% \mathrm{P})=\left(\mathrm{F}_{\mathrm{v}}{ }^{\prime} / \mathrm{F}_{\mathrm{m}}{ }^{\prime}\right) \times \mathrm{qP} \times 100$, and fraction of light absorbed by PSII antenna not used in photochemistry nor dissipated in the antenna $(\% \mathrm{X})=\left(\mathrm{F}_{\mathrm{v}}{ }^{\prime} / \mathrm{F}_{\mathrm{m}}{ }^{\prime}\right) \times(1-\mathrm{qP}) \times 100$.

\subsection{Biomass analysis}

At the end of the experiment, five plants for each species from each OTC were randomly harvested, and their dry weights were determined after oven-drying at $75^{\circ} \mathrm{C}$ until constant weight.

\subsection{Statistics}

Measurements were carried out on five $(n=5)$ replicates for each treatment and species. We note that the lack of treatments replication may raise concerns about pseudo-replication (Hurlbert, 1984). However, we believe the benefit of using more treatments outweighs this limitation, as published by Hewitt et al. (2014) and others. The normality of data was preliminarily tested by the Shapiro-Wilk $W$ test. Ecophysiological data were analyzed using one-way repeated measures analysis of variance (ANOVA), whereas biomass ones were analyzed by one-way ANOVA. Comparisons among means were determined by Fisher LSD post-test. Statistical analyses were performed using SPSS 16.0 computer package.

\section{Results}

\subsection{Visible injury and biomass production}

In smoke tree, $\mathrm{O}_{3}$ visible injury was shown only under $\mathrm{AA}+120$ treatment, at the AOT40 of $13.5 \mathrm{ppm} \mathrm{h}$, in form of brown stains in interveinal areas of the upper surface of older leaves. Then, they spread into patches, finally leading to withered leaves (Fig. 1A). Differently, in marigold plants it emerged in both $A A+60$ and $A A+120$ samples, at the AOT40 of 8.6 and $6.4 \mathrm{ppm}$ h, respectively, in form of leaf yellowing chlorosis covering a large portion of the interveinal areas of leaves (Fig. 1B). No symptoms were detected in rose.

Concerning total biomass production, seedlings of smoke tree were affected only by $A A+120(-32 \%)$, whereas marigold ones were altered even by $A A+60(-29 \%)$ and even more by $A A+120$ ( $-40 \%)$. Conversely, $A A+60$ treatment induced biomass production of rose $(+16 \%)$, while $A A+120$ did not act on this feature (Table 1 ). Taking into account each organ, root biomass production of smoke tree was reduced by 33 and $53 \%$ under $A A+60$ and $A A+120$ treatments, respectively, while leaf and stem biomass productions were only affected by $A A+120$ treatment ( -54 and $-33 \%$, respectively). All parts of marigold were suppressed, with reduction of 13, 25, 35 and 50\% in leaf, stem, flower and root under $A A+60$ treatment, respectively, and $19,40,45$ and $67 \%$ under $A A+120$ one. No organ of rose showed changes under elevated $\mathrm{O}_{3}$, although the total biomass increased in plants exposed to $A A+60$ treatment.

\subsection{Dynamics of gas exchanges}

According to the one-way repeated measures ANOVA, the interaction between $\mathrm{O}_{3}$ and time was significant for all the gas exchange parameters, with the exception of $\mathrm{V}_{\mathrm{cmax}}$ in smoke tree plants (Figs. 2 and 3). Here, $A_{\text {sat }}$ decreased already after one month FBE due to $A A+60$ exposure ( $-22 \%$, in comparison to $A A)$ and even more to $A A+120$ one $(-56 \%)$. After two months FBE, AA plants showed lower values than on the previous measurement $(-23 \%)$, while decreases due to $\mathrm{O}_{3}$-addition were similar between $\mathrm{AA}+60$ and $A A+120$ treatments ( -17 and $-22 \%$, respectively) (Fig. 2A). Differently, only after 30 days $\mathrm{FBE} \mathrm{g}_{\mathrm{s}}$ was lower in AA+60 plants (-29\%) and even more in $\mathrm{AA}+120$ ones $(-52 \%)$ than in those exposed to AA, although $A A$ plants showed a decrease of $g_{s}$ between the measuring times ( $-34 \%$ ) (Fig. 2B). Increased $\mathrm{O}_{3}$ induced changes of $\mathrm{C}_{\mathrm{i}}$ only after 60 days FBE, when its addition to AA leaded to a similar increase 

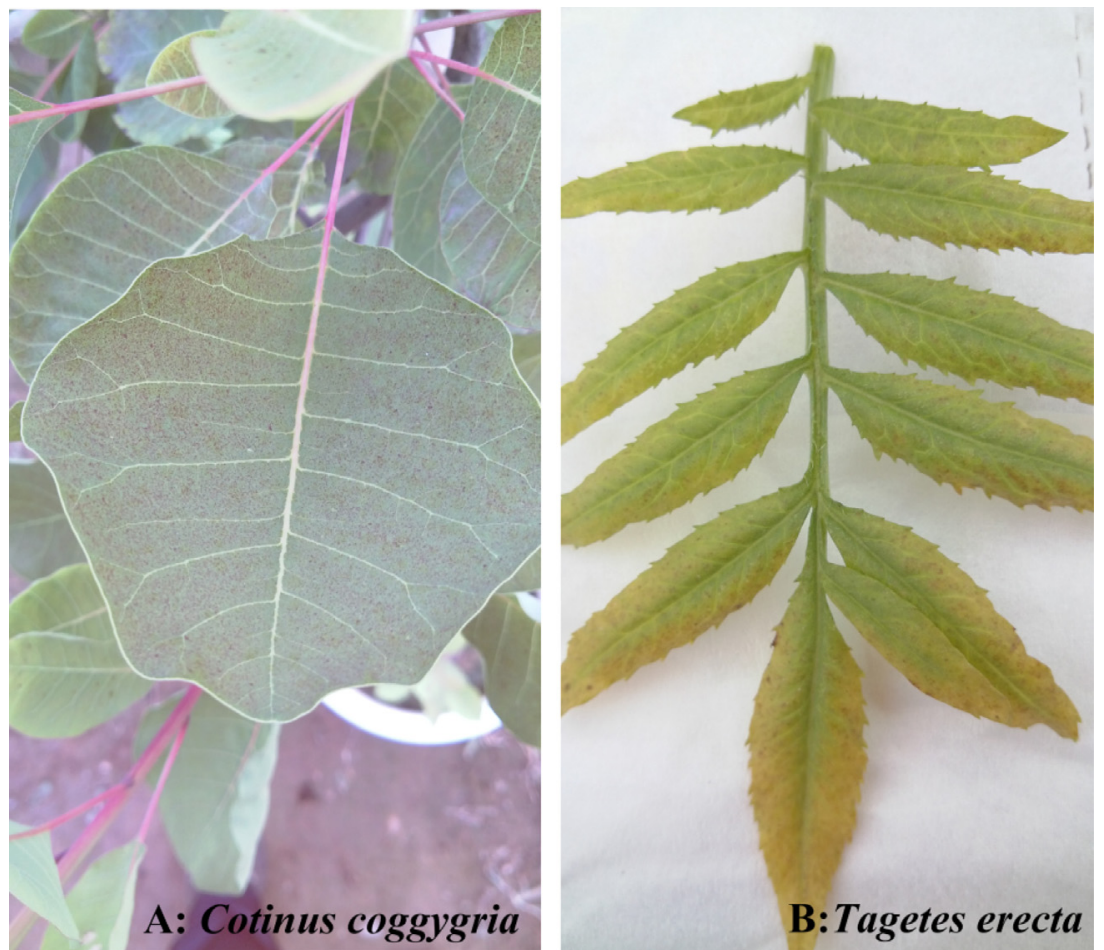

Fig. 1. $\mathrm{O}_{3}$ symptoms on leaves of Cotinus coggygria (A) and Tagetes erecta (B).

of this parameter regardless of the concentration ( +15 and $+18 \%$ in $A A+60$ and $A A+120$ plants in comparison to $A A$ ones, respectively) (Fig. 2C). Differently, $A_{\text {sat }}$ of marigold plants was depressed by $A A+60$ exposure and even more by $A A+120$ one after 17 and 32 days $F B E$ ( -34 and $-67 \%$, firstly; -16 and $-42 \%$, secondly in comparison to AA, respectively) and similar responses were shown in terms of $\mathrm{g}_{\mathrm{s}}(-27$ and $-50 \% ;-32$ and $-67 \%)$. However, AA plants showed a decrease of $A_{\text {sat }}(-23 \%)$ and an increase of $g_{s}(+30 \%)$ throughout the exposure (Fig. 2D, E). Only on the first measuring time, $\mathrm{C}_{\mathrm{i}}$ was affected by $\mathrm{O}_{3}$-addition increasing similarly in $\mathrm{AA}+60$ and $\mathrm{AA}+120$ plants (+12 and $+15 \%$, respectively), although $\mathrm{AA}$ induced a raise of this parameter between 17 and 32 days $\mathrm{FBE}(+9 \%)$ (Fig. 2F). In roses, $A_{\text {sat }}$ showed different responses between times of analysis: firstly, it increased only in $A A+60$ plants (+16\%); secondly, it decreased similarly in both $A A+60$ and $A A+120$ ones $(-30$ and $-43 \%$, respectively). Also in this species, $A_{\text {sat }}$ decreased in AA plants throughout the exposure (-33\%) (Fig. 2G). After 30 days FBE, only $A A+120$ treatment caused a drop of $g_{s}(-35 \%$, in comparison to $A A)$, whereas the following analysis showed a similar decrease of this parameter among plants exposed to $\mathrm{O}_{3}$-addition $(-52$ and $-58 \%$ in $A A+60$ and $A A+120$, respectively), and also $A A$ plants showed lower values then the previous measuring time (-19\%) (Fig. $2 \mathrm{H}$ ). Finally, $\mathrm{C}_{\mathrm{i}}$ was only affected by increased $\mathrm{O}_{3}$ concentrations after two months FBE decreasing under $A A+60$ exposure $(-16 \%$, in comparison to $A A$ ) and increasing under $A A+120$ one (+9\%) (Fig. 2I).

In comparison to $\mathrm{AA}, \mathrm{O}_{3}$-addition induced a drop of $\mathrm{V}_{\mathrm{cmax}}$ of smoke tree only at the second time of analyses, although it is not possible to evaluate the differences among samples since the interaction $\mathrm{O}_{3} \times$ time was not significant, as previously reported (Fig. 3A). Similarly, $\mathrm{J}_{\max }$ and TPU were affected by $\mathrm{O}_{3}$-addition only after 60 days FBE (Fig. $3 B$ and $C$ ): the former parameter decreased due to $A A+60(-26 \%)$ and even more to $A A+120(-51 \%)$, while the second one dropped similarly among treatments $(-31 \%$ and $-34 \%$ in $A A+60$ and $A A+120$ plants, respectively). In marigold plants, $\mathrm{V}_{\mathrm{cmax}}, \mathrm{J}_{\max }$, and TPU showed the same responses at both measuring times (Fig. 3D-F): firstly, they decreased due to AA+60 $(-26$,

Table 1

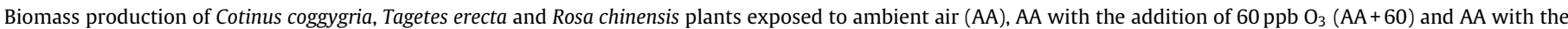

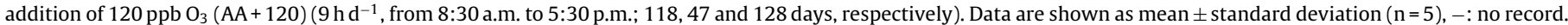
Following one-way ANOVA, for each species different letters indicate significant differences $(P \leq 0.05)$. ${ }^{* * *} P \leq 0.001,{ }^{*} P \leq 0.05$. Abbreviation: DW, dry weight.

\begin{tabular}{|c|c|c|c|c|c|c|}
\hline \multirow[t]{2}{*}{ Plant Species } & \multirow[t]{2}{*}{ Ozone Treatments } & \multicolumn{5}{|c|}{ Biomass Production (g DW plant ${ }^{-1}$ ) } \\
\hline & & Leaf & Stem & Flower & Root & Total \\
\hline \multirow{4}{*}{ Cotinus coggygria } & $\mathrm{AA}$ & $56 \pm 12 b$ & $122 \pm 9 b$ & - & $88 \pm 10 b$ & $265 \pm 8 c$ \\
\hline & $\mathrm{AA}+60$ & $60 \pm 11 b$ & $109 \pm 6 b$ & - & $59 \pm 10$ a & $227 \pm 21 b$ \\
\hline & $\mathrm{AA}+120$ & $26 \pm 7 \mathrm{a}$ & $82 \pm 13 \mathrm{a}$ & - & $41 \pm 9 \mathrm{a}$ & $149 \pm 20 \mathrm{a}$ \\
\hline & Ozone & $*$ & ** & & $* *$ & $* * *$ \\
\hline \multirow{4}{*}{ Tagetes erecta } & $\mathrm{AA}$ & $16 \pm 1 \mathrm{~b}$ & $20 \pm 3 c$ & $20 \pm 2 b$ & $6 \pm 1 b$ & $63 \pm 4 c$ \\
\hline & $\mathrm{AA}+60$ & $14 \pm 1 \mathrm{a}$ & $15 \pm 2 b$ & $13 \pm 2 \mathrm{a}$ & $3 \pm 1 \mathrm{a}$ & $45 \pm 6 b$ \\
\hline & $\mathrm{AA}+120$ & $13 \pm 1 \mathrm{a}$ & $12 \pm 1 \mathrm{a}$ & $11 \pm 2 \mathrm{a}$ & $2 \pm 1 \mathrm{a}$ & $38 \pm 2 \mathrm{a}$ \\
\hline & Ozone & $* *$ & $* * *$ & $* * *$ & $* * *$ & $* * *$ \\
\hline \multirow{4}{*}{ Rosa chinensis } & $\mathrm{AA}$ & $37 \pm 6 a$ & $36 \pm 3 a$ & - & $21 \pm 1 \mathrm{a}$ & $94 \pm 9 \mathrm{a}$ \\
\hline & $\mathrm{AA}+60$ & $40 \pm 7 a$ & $43 \pm 4 a$ & - & $26 \pm 5 a$ & $109 \pm 7 b$ \\
\hline & $\mathrm{AA}+120$ & $31 \pm 2 \mathrm{a}$ & $37 \pm 10 \mathrm{a}$ & - & $24 \pm 3 \mathrm{a}$ & $92 \pm 10 \mathrm{a}$ \\
\hline & Ozone & ns & ns & & ns & $*$ \\
\hline
\end{tabular}



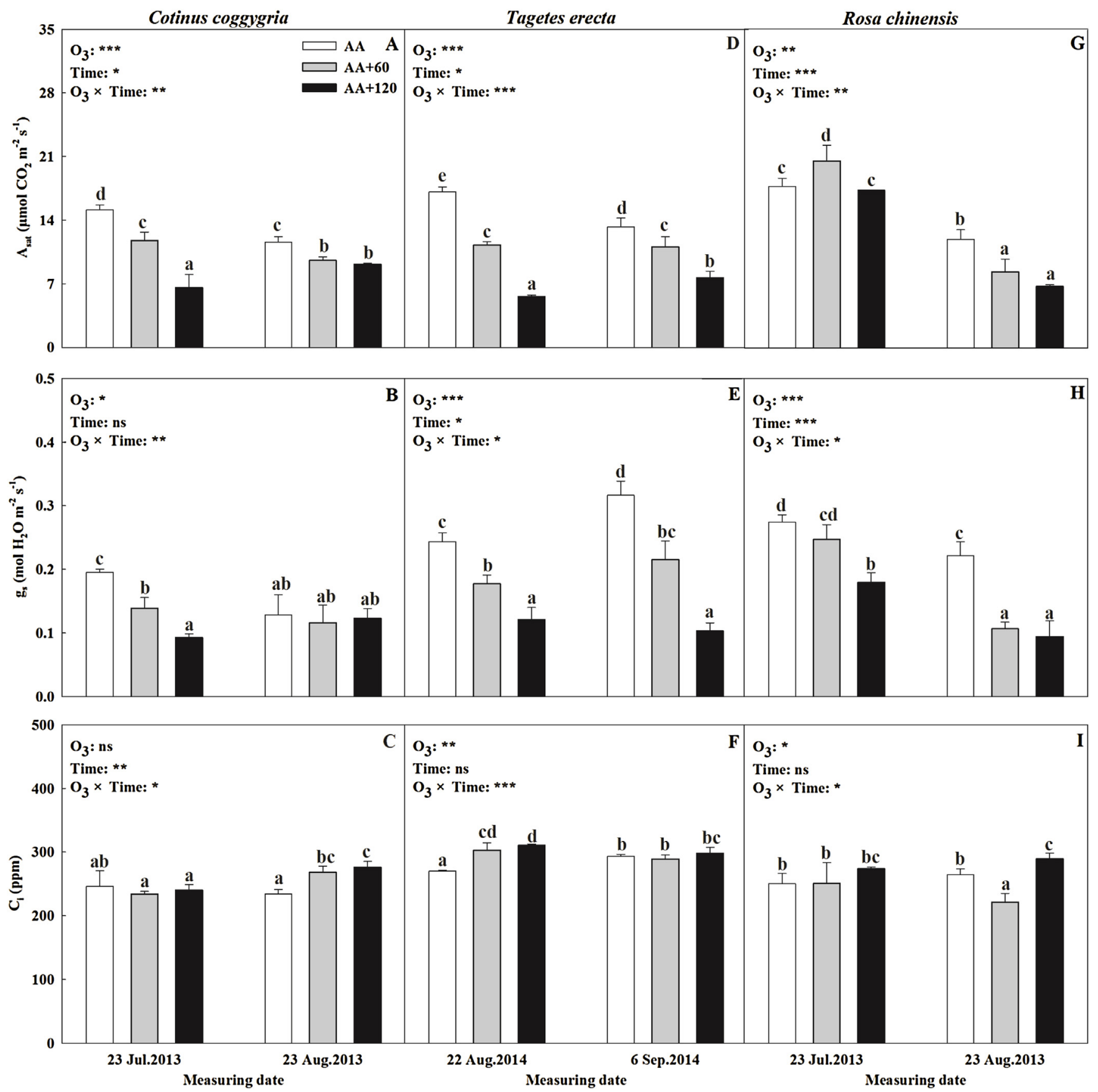

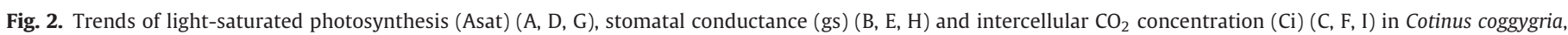

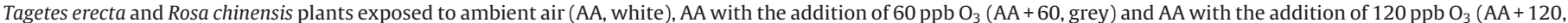

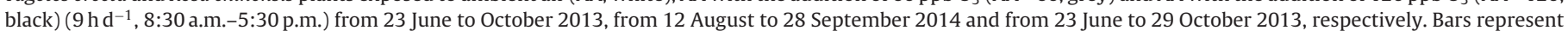

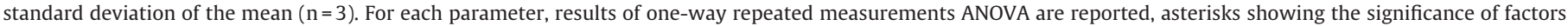
(ozone and time) and their interaction for: ${ }^{* * *} P \leq 0.001,{ }^{* *} P \leq 0.01,{ }^{*} P \leq 0.05$, ns $=P>0.05$. Different letters indicate significant differences $(P \leq 0.05$ ).

-21 , and $-32 \%$ in comparison to $\mathrm{AA}$, respectively) and even more to $A A+120$ treatment $(-60,-59$, and $-72 \%)$, and later only due to $A A+120$ one $(-44,-54$, and $-47 \%)$. Furthermore, these parameters decreased between times of analysis in AA plants $(-36,-31,-25 \%)$. Finally, $V_{\mathrm{cmax}}$, $\mathrm{J}_{\max }$ and TPU of rose plants showed an increase due to $A A+60$ after one month $\mathrm{FBE}(+27,+11$ and $+25 \%$, respectively), while only $\mathrm{J}_{\max }$ was negatively affected by AA+120 ( $\left.-24 \%\right)$. Differently, these parameters showed three different responses after two months FBE: $V_{\text {cmax }}$ decreased only in $A A+120$ plants $(-17 \%)$, $\mathrm{J}_{\text {max }}$ increased only in $\mathrm{AA}+60(+43 \%)$, while TPU was not affected by $\mathrm{O}_{3}$-additon. However, they decreased throughout exposure in AA plants ( $-30,-46$ and $-46 \%$, respectively).

\subsection{Dynamics of chlorophyll a fluorescence}

According to the one-way repeated measures ANOVA, the interaction between $\mathrm{O}_{3}$ and time was not significant for all the chlorophyll $a$ fluorescence parameters in smoke tree plants. Here, only the factor $\mathrm{O}_{3}$ was significant for $\mathrm{F}_{\mathrm{v}}{ }^{\prime} / \mathrm{F}_{\mathrm{m}}$ ', $\Phi_{\mathrm{PSII}}$ and $\mathrm{qP}$ since the gas pollutant decreased these parameters, while $\Phi_{\text {PSII }}$ and qP were significant also in terms of time suggesting that they dropped comparing measuring times (Fig. 4A-C). Marigold plants showed decreases of $\mathrm{F}_{\mathrm{v}}{ }^{\prime} / \mathrm{F}_{\mathrm{m}}$ ' due to $\mathrm{O}_{3}$-addition after 17 days $\mathrm{FBE}$ $(-13 \%$ in $A A+60$ plants and even more in $A A+120$ ones, $-31 \%)$, whereas only $A A+120$ exposure decreased this parameter at the 

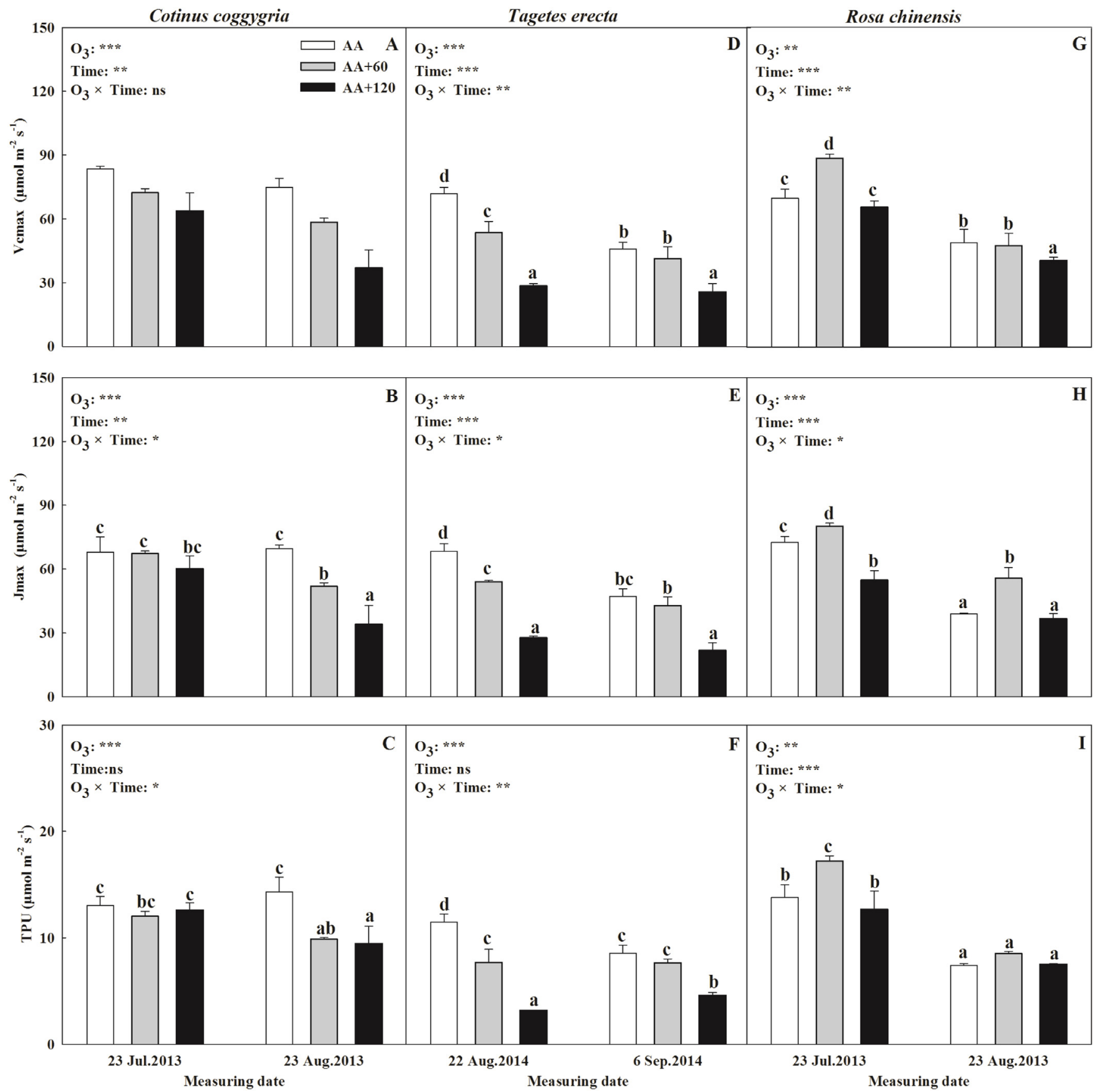

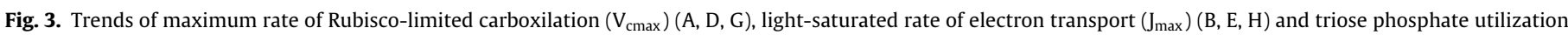

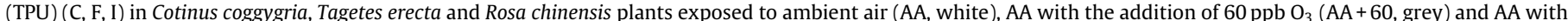

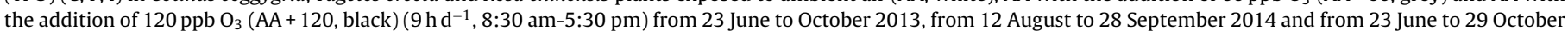

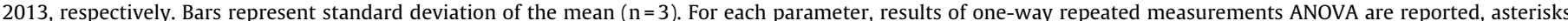

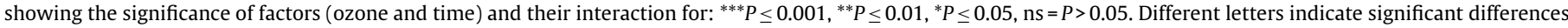
$(P \leq 0.05)$.

following measurement (-16\%), although also AA plants showed a decrease between times of analysis (-6\%) (Fig. 4D). Differently, $\Phi_{\text {PSII }}$ decreased due to AA+60 and even more to AA+120 at both times of measurement ( -26 and $-55 \%,-32$ and $-46 \%$ after 30 and 60 days FBE, respectively). Also $\Phi_{\mathrm{PSII}}$ dropped in AA plants throughout the exposure $(-18 \%$ ) (Fig. $4 \mathrm{E})$. The interaction $\mathrm{O}_{3} \times$ time was not significant for $\mathrm{qP}$ of marigold and $\mathrm{F}_{\mathrm{v}}{ }^{\prime} / \mathrm{F}_{\mathrm{m}}$ ' of rose, although $\mathrm{O}_{3}$ decreased these parameters and their values were lower on the second time of measurement in comparison to the first one (Fig. $4 \mathrm{~F}$, $\mathrm{G})$. In rose plants, $\Phi_{\mathrm{PSII}}$ and qP decreased only due to $\mathrm{AA}+120$ treatment after one month $\mathrm{FBE}$ ( -30 and $-15 \%$, respectively), whereas they were also affected by $A A+60(-26$ and $-10 \%)$ and even more by $A A+120$ ( -60 and $-48 \%)$ at the following analysis. Also for these parameters, AA induced a decrease throughout time ( -12 and $-10 \%$, respectively) (Fig. $4 \mathrm{H}, \mathrm{I}$ ).

Also in terms of distribution of light energy, one-way repeated measures ANOVA showed none $\mathrm{O}_{3} \times$ time interaction in smoke tree. Here, $\mathrm{O}_{3}$ induced a reduction of \% $\mathrm{P}$ and an increase of $\% \mathrm{D}$, but only the latter parameter showed highest values at the second analysis in comparison to the first one (Fig. 5A, B). Differ- 

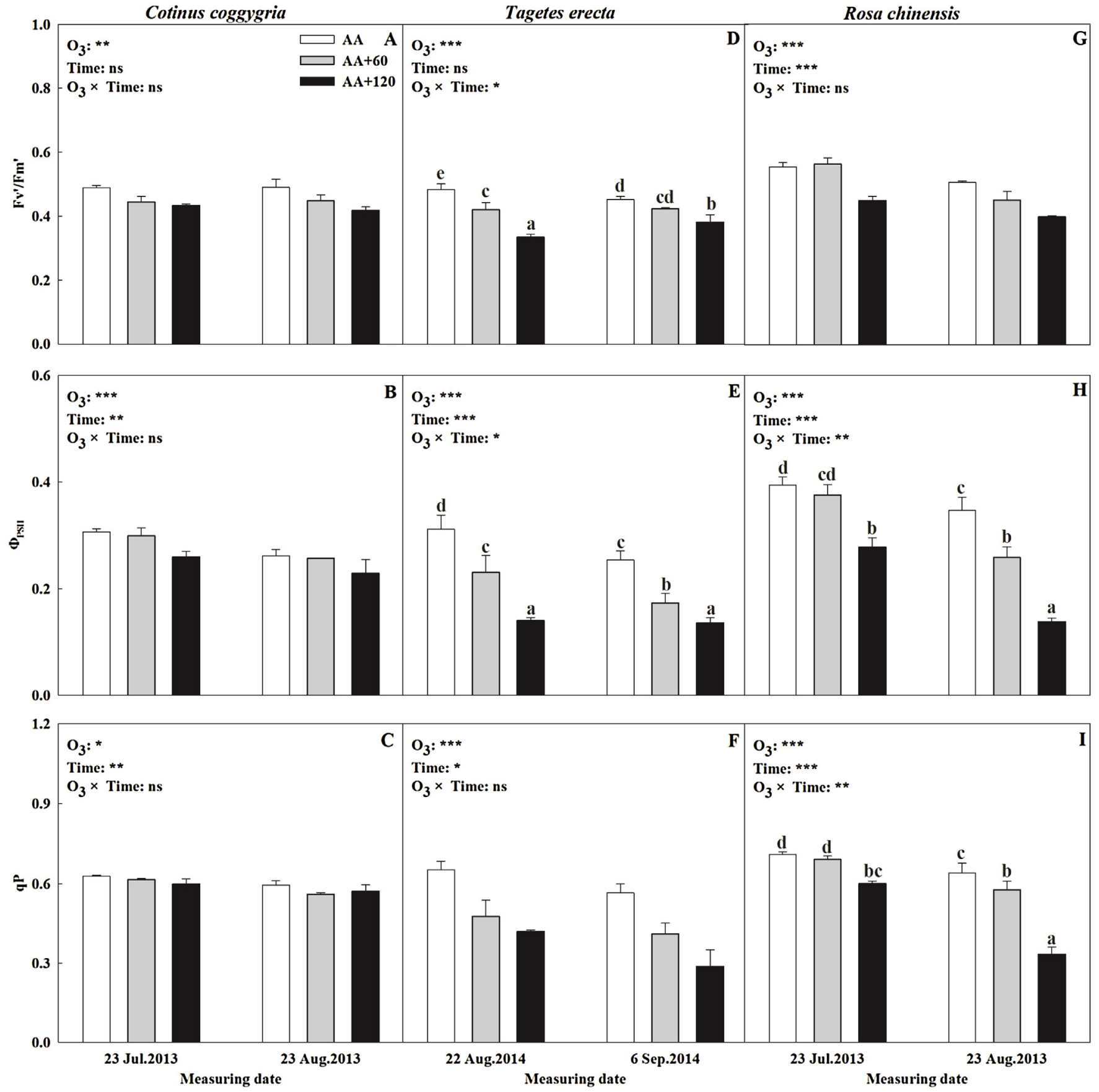

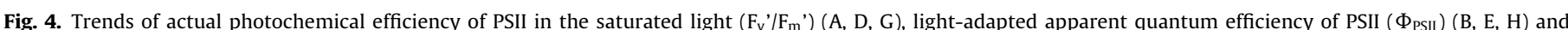

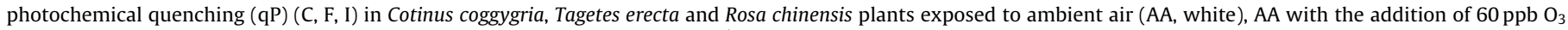

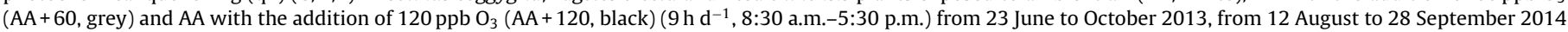

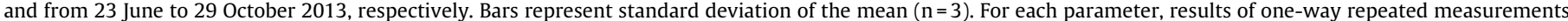

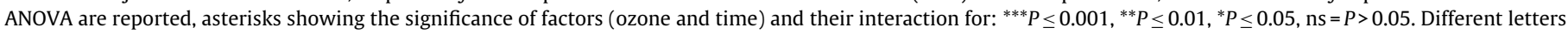
indicate significant differences $(P \leq 0.05)$.

ently, \%X was only affected by $\mathrm{O}_{3}$, but a clear response was not shown throughout the exposure (Fig. 5C). In marigold plants, \% $\mathrm{P}$ decreased after 17 days FBE due to $A A+60$ treatment (-26\%) and even more to $A A+120$ one $(-55 \%)$, whereas dropped similarly in both $A A+60$ and $A A+120$ plants at the following measurement ( -37 and $-46 \%$, respectively). Furthermore, AA plants showed a decrease of this parameter between analyses $(-18 \%)$. Oppositely, $\% \mathrm{D}$ increased in $\mathrm{AA}+60$ and even more in $\mathrm{AA}+120$ plants $(+17$ and $+29 \%$ ) after 17 days FBE and raised only in $A A+120$ ones after 32 days $F B E(+10 \%)$. Here, \%X was affected only by $A A+60$ at the first measuring time $(+27 \%)$, whereas at the second one it increased in $A A+60$ and even more in $A A+120$ treatments $(+19$ and $+44 \%$, respectively). In rose plants, \% $\mathrm{P}$ dropped only due to $\mathrm{AA}+120$ after 30 days $\mathrm{FBE}(-33 \%)$, whereas due to $A A+60$ and even more to $A A+120$ after 60 days $\mathrm{FBE}$ ( -23 and $-59 \%$, respectively). Also AA plants showed a decrease of this parameter between measuring times (-16\%). Oppositely, \%D increased only in AA+120 plants after 30 days $\mathrm{FBE}(+26 \%)$, whereas in $A A+60$ and even more in $A A+120$ plants after 60 days $\mathrm{FBE}(+11$ and $+23 \%$, respectively). AA plants showed an increase of \%D between times of analysis (+11). 

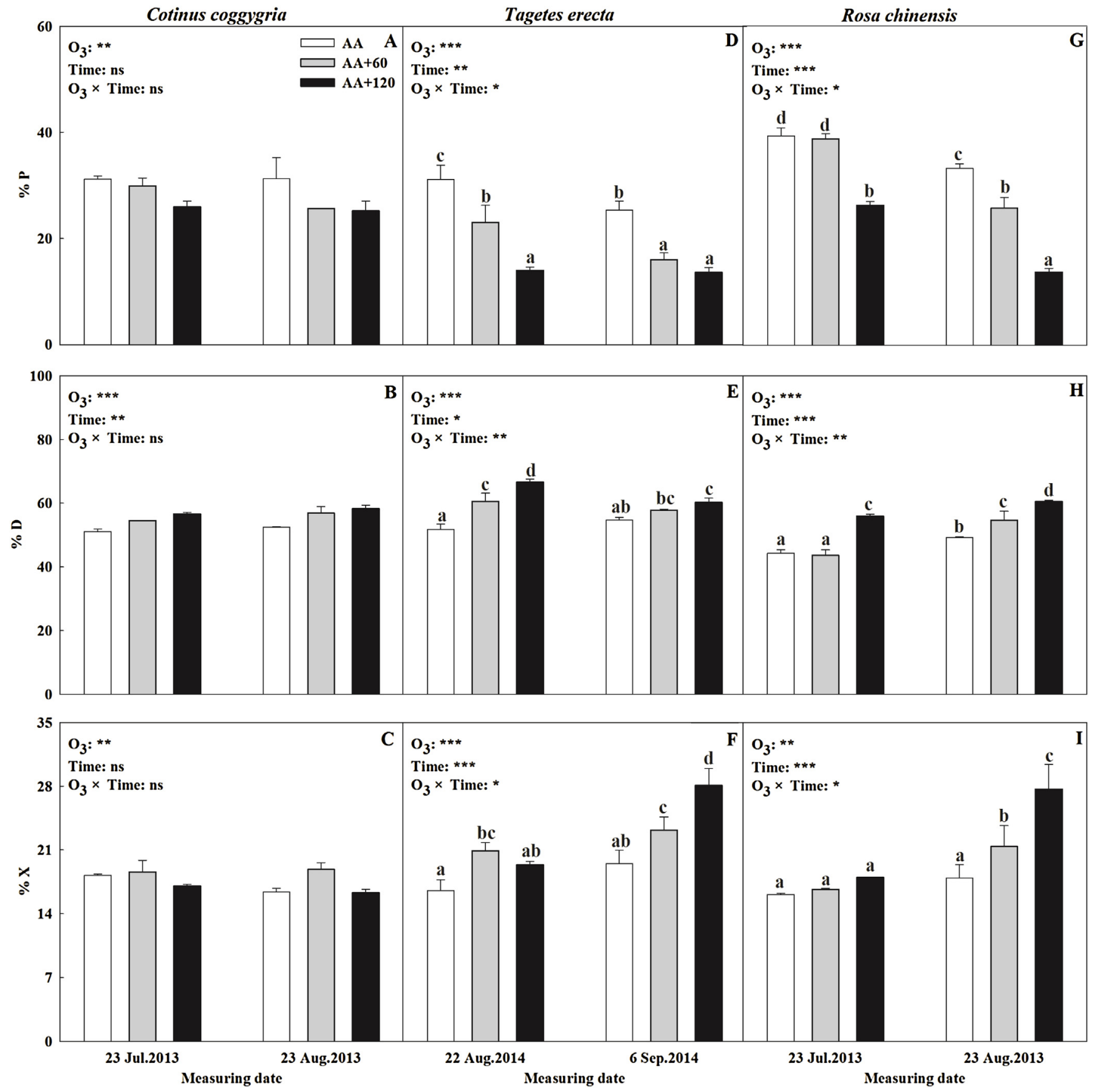

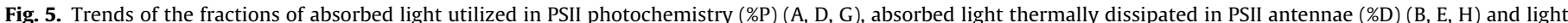

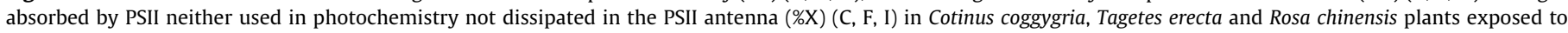

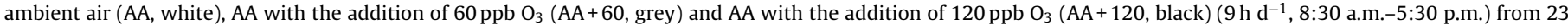

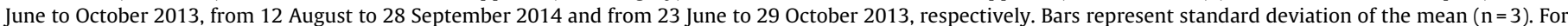

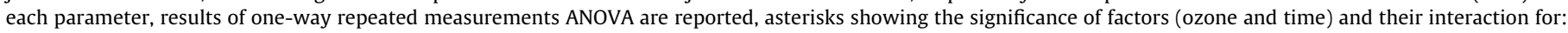
${ }^{* * *} P \leq 0.001,{ }^{* *} P \leq 0.01,{ }^{*} P \leq 0.05, \mathrm{~ns}=P>0.05$. Different letters indicate significant differences $(P \leq 0.05)$.

Finally, $\mathrm{O}_{3}$-addition increased \%X only after 60 days $\mathrm{FBE}:+20 \%$ in $\mathrm{AA}+60$ plants and even more in $\mathrm{AA}+120$ ones $(+55 \%)$.

\section{Discussion}

Results of the present study show some of the integrated photophysiological mechanisms that may confer $\mathrm{O}_{3}-$ sensitivity/tolerance to smoke tree, marigold and rose seedlings, evaluated to improve their management in UGS responding to climate change.
Plant sensitivity to $\mathrm{O}_{3}$ is generally identified by the timing or extent of leaf injury (Bermejo et al., 2003; Li et al., 2015). On this basis, smoke tree and even more marigold seem to be $\mathrm{O}_{3}$ sensitive, whereas rose should be considered tolerant. However, for some species (e.g. Soja et al., 1998), impairments of photosynthesis occurred prior to visible injury formation, which may lead to decrease in biomass production in the absence of visible injury (Pleijel et al., 1999). Therefore, biomass variation reflected by inhibited photosynthesis may be considered as an earlier indicator than visible injury to assess plant tolerance to the pollutant gas, 
especially at low $\mathrm{O}_{3}$ concentrations (Pleijel et al., 1999). Also following this approach, smoke tree and marigold showed an $\mathrm{O}_{3}$ sensitivity since their total biomass tended to decrease chasing the concentration gradient of $\mathrm{O}_{3}$. In rose plants, differently, biomass increased under $A A+60$ treatment and was not affected under $\mathrm{AA}+120$ one compared to AA seedlings, showing again a greater $\mathrm{O}_{3}$-tolerance of this species. The $\mathrm{O}_{3}$-induced biomass increment has been previously reported. Prozherina et al. (2003), for instance, recorded a similar increase by $4-18 \%$ in young birch genotypes

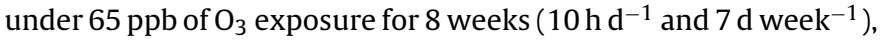
mainly attributed to a delay in bud burst. Similar results were also found in 1.5-1.7 $\times$ ambient $\mathrm{O}_{3}$-treated birch genotypes with different root-shoot ratio responses (Yamaji et al., 2003).

Photosynthesis is the physiological foundation of biomass formation, which can be regulated by stomatal and/or non-stomatal factors (Zhang et al., 2014). In our study, $\mathrm{O}_{3}$ exposure reduced photosynthetic efficiency in all seedlings, as largely reported in previous studies on several species (e.g. Flowers et al., 2007; Pellegrini et al., 2011; Zhang et al., 2011; Cotrozzi et al., 2016). However, different features were shown by the three species here monitored throughout the experiment (to be quite clear, comparisons among species is not the aim of the present study). In smoke tree plants, already at the first measuring time (one month $\mathrm{FBE}$ ) $\mathrm{O}_{3}$-addition induced a reduction of $\mathrm{CO}_{2}$ assimilation following the concentration gradient of the pollutant gas. Currently, there is debate regarding the principal mechanism that induces decrease in photosynthetic rate, with evidence of direct effects of $\mathrm{O}_{3}$ on light and dark reactions of photosynthesis (Power and Ashmore, 2002) or through an indirect stomatal closure effect (Noormets et al., 2001). Here, both stomatal and mesophyllic limitations were shown. However, the alterations at mesophyll level seemed to be diffusional rather than biochemical since $\mathrm{V}_{\mathrm{cmax}}$, $\mathrm{J}_{\max }$ and TPU did not decrease in comparison to AA plants. This behavior has been observed by other authors in several species (e.g. Sun et al., 2014). The constraint in photoassimilation seemed to be not ascribable also to light reactions of photosynthesis considering that the PSII performance and the distribution of light energy were not largely affected by $\mathrm{O}_{3}$ and did not follow the behaviors of gas exchange parameters in both times of analysis. The scenario changed at the second measuring time (two months FBE). At this point, the oxidative pressure presumably became stronger since also plants exposed only to AA showed a reduction of $A_{\text {sat }}$ in comparison to the previous analysis, confirming an high $\mathrm{O}_{3}$-sensitivity of this species. Furthermore, at this time, no more differences were shown between $A A+60$ and $A A+120$ in terms of photosynthetic rate, suggesting that all plants exposed to increasing $\mathrm{O}_{3}$ might have reached a lower bound level. Although there were no differences in $g_{s}$ among treatments, we speculate that all plants greatly closed stomata since their values were at the same levels shown by AA +120 plants one month before. Thus, the stomatal limitation seems to be the Achille's heel of this species as previously reported for other species (e.g. Ginkgo biloba; He et al., 2007). However, also the mesophyll impairments in photochemistry $\mathrm{CO}_{2}$ fixation seemed to be more drastic at the second measuring time since the values of $C_{i}$ were higher in plants exposed to $\mathrm{O}_{3}$-addition than those exposed only to AA. Indeed, after 60 days FBE, these plants began to show decreases in Rubisco carboxylation efficiency and regeneration capacity (especially in AA +120 ones), as well as in TPU. However, interestingly, smoke tree was the only species where in AA these parameters did not decrease throughout time, confirming that the stomatal limitation might be its principal weakness.

At the first measuring time also marigold showed a contraction of $\mathrm{CO}_{2}$ assimilation twinned to both reduction of $\mathrm{O}_{3}$ uptake and store of $\mathrm{CO}_{2}$ in substomatal chamber, with $\mathrm{A}_{\mathrm{sat}}$ and $\mathrm{g}_{\mathrm{s}}$ decreasing following the gradient of $\mathrm{O}_{3}$ concentration, and $\mathrm{C}_{\mathrm{i}}$ reaching higher values than AA plants. However, differently to smoke tree, here the responsibility seemed to be more ascribable to a mesophyllic limitation since $\mathrm{V}_{\mathrm{cmax}}$, $\mathrm{J}_{\max }$ and TPU decreased due to $\mathrm{O}_{3}$ addition, again following the concentration gradient of the pollutant gas. Many Authors (Calatayud et al., 2007; Pina and Moraes, 2010; Pellegrini et al., 2011) similarly found that $\mathrm{O}_{3}$-induced differences in photosynthesis are the result of non-stomatal factors, potentially driven by either photosystem oxidation, (i) limiting the energy for RuBP regeneration from the lower pools of Calvin cycle intermediates, (ii) decreasing the efficiency of Rubisco due to direct enzyme oxidation or (iii) reducing $\mathrm{CO}_{2}$ transport to the enzymes. Furthermore, previous studies reported that the limitation of photosynthesis is correlated with the reduction in the efficiency of energy conversion of PSII as shown by decreased ability of electron transport chain and reduced quinone pool (Thwe et al., 2014). This outcome leads to speculate that the limitation of photoassimilation might be also due to contractions of light reactions of photosynthesis, which could be explained as a chronic photoinhibition or a consequence of the decline in demand for reducing power and energy (NADPH and ATP, Pellegrini, 2014). Moreover, the effects of oxidative stress on photosynthetic process were well represented by data obtained from the analysis of energy distribution. Increasing $\mathrm{O}_{3}$ limited the photosynthetic process in $A A+60$ and $A A+120$ plants (as indicated by $\% \mathrm{P}$ ), distributing the excess of energy into thermal dissipation (\%D increased) and in alternative ways in AA +60 ones (\% increased), according to Calatayud et al. (2002). Other divergences with smoke tree emerged at the second measuring time (two months FBE) since $A_{\text {sat }}, g_{s}$ and $C_{i}$ showed similar behaviors than 15 days before. Although $\mathrm{A}_{\text {sat }}$ was negatively affected also by AA (in comparison to the previous measurement), confirming that also this species is $\mathrm{O}_{3}$ sensitive, differences between $\mathrm{O}_{3}$-addition treatments were still present in gas exchange parameters. These responses suggest that $\mathrm{AA}+60$ plants were still able to partially defend themselves from the oxidative pressure. This outcome looked like to be twinned to a capacity of these plants to protect their dark reactions of photosynthesis since $\mathrm{V}_{\mathrm{cmax}}$, $\mathrm{J}_{\max }$ and TPU decreased only under $\mathrm{AA}+120$ treatment. Moreover, an ability of marigold exposed to $A A+60$ to enact some antioxidant mechanisms seemed to be confirmed by the behavior in PSII performance. Indeed, in these plants the exposure leaded only to a photoinhibition and not to a chronic photodamage. Certainly, it is known that plants have very efficient enzymatic and non-enzymatic antioxidant mechanisms which work in concert to control the cascades of uncontrolled oxidation and protect cells from oxidative damage by scavenging reactive oxygen species (Gill and Tuteja, 2010). We can speculate that these responses of $A A+60$ plants were presumably due to their ability to reduce the energy addressed to photosynthesis, dissipating it not as heat but in alternative ways. However, marigold could not carry out similar responses under the highest $\mathrm{O}_{3}$ concentration. Thus, in this species the reduction of photosynthetic performance and consequently of biomass production seemed to be mainly ascribable to impairments of light and dark reactions of photosynthesis. In this case, stomata closure maybe not the cause to limit photosynthetic rate, but the down-regulated response to decreased carbon assimilation to balance the $\mathrm{CO}_{2}$ concentration between ambient and the substomatal chamber (Watanabe et al., 2014).

A third different response to $\mathrm{O}_{3}$ throughout the exposure was shown by rose plants. After one month $\mathrm{FBE}$, unexpectedly, $\mathrm{CO}_{2}$ assimilation rate increased in plants exposed to $A A+60$ and did not change in the $A A+120$ ones, confirming the behavior in biomass production. This phenomenon confirmed something already indicated by the other species: photosynthesis behavior of the first period was more closely related to the final biomass productions since initially leaves were in better conditions facilitating carbohydrate accumulation, while later their health went bad (i.e. due to lipid peroxidation or chlorophyll degradation); (Feng et al., 2011b). This phenomenon was partially supported by trends of $g_{s}, C_{i}, V_{c m a x}$, 
$J_{\max }$ and TPU. In AA+60 plants, neither stomatal nor mesophyllic limitations were shown. Particularly, the increment in $A_{\text {sat }}$ of $A A+60$ plants seemed ascribable to a better efficacy of dark reactions of photosynthesis ( $\mathrm{V}_{\mathrm{cmax}}, \mathrm{J}_{\max }$ and TPU increased). Probably, it could be due to an antioxidant capacity of these plants, allowing them to cope with $\mathrm{O}_{3}$ stress. Indeed, also PSII performance and the distribution of light energy were not affected by the exposure. Also in $A A+120$ seedlings, although the light constraints at stomatal and mesophyllic levels, in Rubisco regeneration capacity and in light reactions of photosynthesis, $A_{\text {sat }}, V_{\text {cmax }}$ and TPU were not affected by the high concentration of the pollutant gas. Still more than $25 \%$ of captured light energy was utilized in PSII photochemistry, which cannot limit the reducing power and energy for biochemical processes (Dubinsky, 1980; Niyogi, 1999). Thus, the higher $\mathrm{O}_{3}$-tolerance of rose was again certified, similarly to other several species (Prozherina et al., 2003; Yamaji et al., 2003). A different situation took place after 60 days FBE. At this point, there was a ruin of $\mathrm{CO}_{2}$ assimilation already in plants exposed to only AA (in comparison to the previous analysis), and a further decrease happened due to $\mathrm{O}_{3}$-addition (similarly among treatments). These falls could be ascribable to stomatal limitations since $g_{s}$ showed the same trend of $A_{\text {sat }}$, while the mesophyllic were shown only in plants exposed to $A A+120$. Anyway, also at this time point, dark reactions of photosynthesis seemed to be the strong point of this species, considering the ability of $\mathrm{AA}+60$ plants to preserve these exercises as demonstrated by unchanged values of $V_{c m a x}$ and TPU, as well as higher ability in Rubisco regeneration. Furthermore, in AA+120 plants the $C_{i}$ increment seemed to be mainly due to a diffusional issue, although also a biochemical one could has occurred since a slight decrease in $\mathrm{V}_{\mathrm{cmax}}$ was observed ( $\mathrm{J}_{\max }$ and TPU were not affected). However, reductions of $A_{\text {sat }}$ might also be ascribable to impairments of efficiency of PSII photochemistry (reduced $\mathrm{F}_{\mathrm{v}}{ }^{\prime} / \mathrm{F}_{\mathrm{m}}$ ' and $\Phi_{\text {PSII }}$ ) and a reduced capacity for reoxidizing $\mathrm{Q}_{\mathrm{A}}$ during actinic illumination (reduced qP, Pellegrini et al., 2015). This outcome was also confirmed by decreased \%P. Despite $A_{\text {sat }}$ decreased similarly among plant exposed to $\mathrm{O}_{3}$-addition, the oxidative pressure of light reactions of photosynthesis was less in $\mathrm{AA}+60$ seedlings, as confirmed also by the distribution of light energy. Thus, an ability of roses to cope with $\mathrm{O}_{3}$ was shown also after two months of exposure.

\section{Conclusions}

Considering biomass production, smoke tree and marigold seem to be $\mathrm{O}_{3}$-sensitive, whereas rose should be considered more tolerant. In our study, the exposure to the pollutant gas reduced photosynthetic efficiency in all species. However, different features were shown throughout the experiment by the three species here monitored: regarding smoke tree, stomatal limitations of photosynthesis seemed to be its principal weakness; differently, in marigold, the reduction of photosynthetic performance and consequently biomass production, was mainly ascribable to impairments of both light and dark reactions of photosynthesis (here, stomatal closure maybe not the cause to limit the photosynthetic rate, but a down-regulated response); finally, rose showed a better efficacy in dark reactions of photosynthesis, probably due to an antioxidant capacity able to preserve the photosynthetic biochemical processes, which could be the reason of its less sensitivity to the pollutant.

In conclusion, the results of this study indicate that non-invasive methods as gas exchange and chlorophyll fluorescence for monitoring photosynthetic performance of urban plants can be useful to give guidelines to ameliorate the management in UGS in the "climate change era". Generally, in severe $\mathrm{O}_{3}$-polluted areas as those of several cities of China, the plants with high-efficient biochemical processes driving a well photosynthetic performance (such as rose) might be a recommended choice. Further studies involving more urban plants are needed since each species, as merged by this study, has its own photophysiological features to cope with $\mathrm{O}_{3}$ stress.

\section{Acknowledgements}

This study was supported by the National Natural Science Foundation of China (No. 31200295). We thank Yulong Zhang from the State Key Laboratory of Urban and Regional Ecology, Research Center for Eco-Environmental Sciences, Beijing, who assisted in building the infrastructure for the $\mathrm{O}_{3}$ fumigation and sample collection. We also would like to thank Cristina Nali (Department of Agriculture, Food and Environment, University of Pisa, Italy) for revising the manuscript.

\section{References}

Avnery, S., Mauzerall, D.L., Liu, J., Horowitz, L.W., 2011. Global crop yield reductions due to surface ozone exposure: 2. Year 2030 potential crop production losses and economic damage under two scenarios of $\mathrm{O}_{3}$ pollution. Atmos. Environ. 45, 2297-2309.

Bermejo, V., Gimeno, B., Sanz, J., De La Torre, D., Gil, J., 2003. Assessment of the ozone sensitivity of 22 native plant species from Mediterranean annual pastures based on visible injury. Atmos. Environ. 37, 4667-4677.

Calatayud, A., Alvarado, J., Barreno, E., 2002. Similar effects of ozone on four cultivars of lettuce in open top chambers during winter. Photosynthetica 40, $195-200$.

Calatayud, V., Cerveró, J., Sanz, M.J., 2007. Foliar, physiologial and growth responses of four maple species exposed to ozone. Water Air Soil Pollut. 185, 239-254.

Calfapietra, C., Peñuelas, J., Niinemets, Ü., 2015. Urban plant physiology: adaptation-mitigation strategies under permanent stress. Trends Plant Sci. 20, $72-75$.

Chen, W.Y., Jim, C., 2008. Assessment and valuation of the ecosystem services provided by urban forests. In: Carreiro, M.M., Song, Y.C., Wu, J.G. (Eds.), Ecology, Planning, and Management of Urban Forests: International Perspectives. Springer, pp. 53-83.

Chen, Y., Wang, X., Jiang, B., Yang, N., Li, L., 2016. Pavement induced soil warming accelerates leaf budburst of ash trees. Urban For. Urban Green. 16, 36-42.

Chuwah, C., van Noije, T., van Vuuren, D.P., Stehfest, E., Hazeleger, W., 2015. Global impacts of surface ozone changes on crop yields and land use. Atmos. Environ. $106,11-23$.

Cotrozzi, L., Remorini, D., Pellegrini, E., Landi, M., Massai, R., Nali, C., Guidi, L., Lorenzini, G., 2016. Variations in physiological and biochemical traits of oak seedlings grown under drought and ozone stress. Physiol. Plant. 157, 69-84.

de Leew, F.A.A.M., van Zantwoort, E.D.G., 1997. Mapping of exceedances of ozone critical levels for crops and forest trees in the Netherlands. Environ. Pollut. 96, 89-98.

Demmig-Adams, B., Adams III, W.W., Barker, D.H., Logan, B.A., Bowling, D.R., Verhoeven, A.S., 1996. Using chlorophyll fluorescence to assess the fraction of absorbed light allocated to thermal dissipation of excess excitation. Physiol. Plant. 98, 253-264.

Dubinsky, Z., 1980. Light utilization efficiency in natural phytoplankton communities. In: Falkowski, P. (Ed.), Primary Productivity in the Sea. Springer, US, pp. 83-97.

Feng, Z., Niu, J., Zhang, W., Wang, X., Yao, F., Tian, Y., 2011a. Effects of ozone exposure on sub-tropical evergreen Cinnamomum camphora seedlings grown in different nitrogen loads. Trees 25, 617-625

Feng, Z., Pang, J., Kobayashi, K., Zhu, J., Ort, D.R., 2011b. Differential responses in two varieties of winter wheat to elevated ozone concentration under fully open-air field conditions. Global Change Biol. 17, 580-591.

Feng, Z., Sun, J., Wan, W., Hu, E., Calatayud, V., 2014. Evidence of widespread ozone-induced visible injury on plants in Beijing, China. Environ. Pollut. 193, 296-301.

Fiscus, E.L., Booker, F.L., Burkey, K.O., 2005. Crop responses to ozone: uptake, modes of action, carbon assimilation and partitioning. Plant Cell Environ. 28, 997-1011.

Flowers, M.D., Fiscus, E.L., Burkey, K.O., Booker, F.L., Dubois, J.-J.B., 2007. Photosynthesis chlorophyll fluorescence, and yield of snap bean (Phaseolus vulgaris L.) genotypes differing in sensitivity to ozone. Environ. Exp. Bot. 61, 190-198.

Ghude, S.D., Jena, C., Chate, D., Beig, G., Pfister, G., Kumar, R., Ramanathan, V., 2014 Reductions in India's crop yield due to ozone. Geophys. Res. Lett. 41, 5685-5691.

Gill, S.S., Tuteja, N., 2010. Reactive oxygen species and antioxidant machinery in abiotic stress tolerance in crop plants. Plant Physiol. Biochem. 48, 909-930.

Gilliland, N., Chappelka, A., Muntifering, R., Ditchkoff, S., 2016. Changes in southern Piedmont grassland community structure and nutritive quality with future climate scenarios of elevated tropospheric ozone and altered rainfall patterns. Plant Biol. (Stuttg.) 18, 47-55. 
Gomes, F., Oliva, M., Mielke, M., de Almeida, A.F., Leite, H., 2006. Photosynthetic irradiance-response in leaves of dwarf coconut palm (Cocos nucifera L. 'nana', Arecaceae): comparison of three models. Sci. Hortic. 109, 101-105.

He, X.-Y., Fu, S.-L., Chen, W., Zhao, T.-H., Xu, S., Tuba, Z., 2007. Changes in effects of ozone exposure on growth, photosynthesis, and respiration of Ginkgo biloba in Shenyang urban area. Photosynthetica 45, 555-561.

Hewitt, D.K.L., Mills, G., Hayes, F., Wilkinson, S., Davies, W., 2014. Highlighting the threat from current and near-future ozone pollution to clover in pasture. Eniron. Pollut. 189, 111-117.

Hurlbert, S.H., 1984. Pseudoreplication and the design of ecological field experiments. Ecol. Monogr. 54, 187-211.

Jo, H.-K., 2002. Impacts of urban greenspace on offsetting carbon emissions for middle Korea. J. Environ. Manage. 64, 115-126.

Li, Y., Zhao, H., Duan, B., Korpelainen, H., Li, C., 2011. Effect of drought and ABA on growth, photosynthesis and antioxidant system of Cotinus Coggygria seedlings under two different light conditions. Environ. Exp. Bot. 71, 107-113.

Li, Q., Song, J., Zhang, J., Yu, W., Hu, H., 2013. Dynamics in the effect of China' urbanization on air quality. Acta Sci. Circumstantiae 33, 2402-2411 (in Chinese, with English abstract)

Li, L., Manning, W.J., Tong, L., Wang, X., 2015. Chronic drought stress reduced but not protected Shantung maple (Acer truncatum Bunge) from adverse effects of ozone $\left(\mathrm{O}_{3}\right)$ on growth and physiology in the suburb of Beijing, China. Environ. Pollut. 201, 34-41.

Lorenzini, G., Nali, C., 2015. A challenging job: plant pathology in the urban environment. Agrochimica, 206-221, VOL. LVIII-No. 3.

Lorenzini, G., Nali, C., Biagioni, M., 1995. Long range transport of photochemical ozone over the Tyrrhenian Sea demonstrated by a new miniaturized bioassay with ozone-sensitive tobacco seedlings. Sci. Total Environ. 166, 193-199.

Matyssek, R., Günthardt-Goerg, M.S., Keller, T., Scheidegger, C., 1991. Impairment of gas exchange and structure in birch leaves (Betula pendula) caused by low ozone concentrations. Trees 5, 5-13.

Morgan, P.B., Bernacchi, C.J., Ort, D. R., Long S.P., 2004. An in vivo analysis of the effect of season-long open-air elevation of ozone to anticipated 2050 levels on photosynthesis in soybean. Plant Physiol. 135, 2348-2357.

Niyogi, K.K., 1999. Photoprotection revisited: genetic and molecular approaches. Annu. Rev. Plant Biol. 50, 333-359.

Noormets, A., Sober, A., Pell, E., Dickson, R., Podila, G., Sober, J., Isebrands, J., Karnosky, D., 2001. Stomatal and non-stomatal limitation to photosynthesis in two trembling aspen (Populus tremuloides Michx.) clones exposed to elevated $\mathrm{CO}_{2}$ and/or $\mathrm{O}_{3}$. Plant Cell Environ. 24, 327-336.

Pellegrini, E., Francini, A., Lorenzini, G., Nali, C., 2011. PSII photochemistry and carboxylation efficiency in Liriodendron tulipifera under ozone exposure. Environ. Exp. Bot. 70, 217-226.

Pellegrini, E., Francini, A., Lorenzini, G., Nali, C., 2015. Ecophysiological and antioxidant traits of Salvia officinalis under ozone stress. Environ. Sci. Pollut. Res. 22, 13083-13093.

Pellegrini, E., 2014. PSII photochemistry is the primary target of oxidative stress imposed by ozone in Tilia americana. Urban For. Urban Green. 13, 94-102.

Pina, J.M., Moraes, R.M., 2010. Gas exchange, antioxidants and foliar injuries in saplings of a tropical woody species exposed to ozone. Ecotoxicol. Environ. Saf. 73, 685-691.

Pleijel, H., Norberg, P.A., Sellden, G., Skärby, L., 1999. Tropospheric ozone decreases biomass production in radish plants (Raphanus sativus) grown in rural south-west Sweden. Environ. Pollut. 106, 143-147.
Power, S., Ashmore, M., 2002. Responses of fen and fen-meadow communities to ozone. New Phytol. 156, 399-408.

Proietti, C., Anav, A., De Marco, A., Sicard, P., Vitale, M., 2016. A multi-sites analysis on the ozone effects on Gross Primary Production of European forests. Sci. Total Environ. 556, 1-11.

Prozherina, N., Freiwald, V., Rousi, M., Oksanen, E., 2003. Interactive effect of springtime frost and elevated ozone on early growth, foliar injuries and leaf structure of birch (Betula pendula). New Phytol. 159, 623-636.

Riaz, A., Younis, A., Taj, A.R., Karim, A., Tariq, U., Munir, S., Riaz, S., 2013. Effect of drought stress on growth and flowering of marigold (Tagetes erecta L.). Pak. J. Bot. 45, 123-131.

Soja, G., Pfeifer, U., Soja, A.M., 1998. Photosynthetic parameters as early indicators of ozone injury in apple leaves. Physiol. Plant. 104, 639-645.

Sun, J., Feng, Z., Ort, D.R., 2014. Impacts of rising tropospheric ozone on photosynthesis and metabolite levels on field grown soybean. Plant Sci. 226, $147-161$.

Thwe, A., Vercambre, G., Gautier, H., Gay, F., Phattaralerphong, J., Kasemsap, P., 2014. Response of photosynthesis and chlorophyll fluorescence to acute ozone stress in tomato (Solanum lycopersicum Mill.). Photosynthetica 52, 105-116.

van Iersel, M., Seymour, L., 2002. Temperature effects on photosynthesis, growth respiration: and maintenance respiration of marigold. XXVI International Horticultural Congress: Elegant Science in Floriculture vol. 624, 549-554

Watanabe, M., Hoshika, Y., Koike, T., 2014. Photosynthetic responses of Monarch birch seedlings to differing timings of free air ozone fumigation. J. Plant Res. 127, 339-345.

Yamaji, K., Julkunen-Tiitto, R., Rousi, M., Freiwald, V., Oksanen, E., 2003. Ozone exposure over two growing seasons alters root-to-shoot ratio and chemical composition of birch (Betula pendula Roth). Global Change Biol. 9, 1363-1377.

Yi, F., Jiang, F., Zhong, F., Zhou, X., Ding, A., 2016. The impacts of surface ozone pollution on winter wheat productivity in China-an econometric approach. Environ. Pollut. 208, 326-335

Yuan, X., Calatayud, V., Jiang, L., Manning, W.J., Hayes, F., Tian, Y., Feng, Z., 2015 Assessing the effects of ambient ozone in China on snap bean genotypes by using ethylenediurea (EDU). Environ. Pollut. 205, 199-208.

Zhang, W.W., Niu, J.F., Wang, X.K., Tian, Y., Yao, F.F., Feng, Z.Z., 2011. Effects of ozone exposure on growth and photosynthesis of the seedlings of Liriodendron chinense (Hemsl.) Sarg, a native tree species of subtropical China. Photosynthetica 49, 29-36.

Zhang, W., Feng, Z., Wang, X., Niu, J., 2014. Elevated ozone negatively affects photosynthesis of current-year leaves but not previous-year leaves in evergreen Cyclobalanopsis glauca seedlings. Environ. Pollut. 184, 676-681.

Zheng, Y., Shimizu, H., Barnes, J., 2002. Limitations to $\mathrm{CO}_{2}$ assimilation in ozone-exposed leaves of Plantago major. New Phytol. 155, 67-78.

Zheng, F., Wang, X., Lu, F., Hou, P., Zhang, W., Duan, X., Zhou, X., Ai, Y., Zheng, H., Ouyang, Z., 2011. Effects of elevated ozone concentration on methane emission from a rice paddy in Yangtze River Delta, China. Global Change Biol. 17 898-910.

Zheng, F., Wang, X., Zhang, W., Hou, P., Lu, F., Du, K., Sun, Z., 2013. Effects of elevated $\mathrm{O}_{3}$ exposure on nutrient elements and quality of winter wheat and rice grain in Yangtze River Delta, China. Environ. Pollut. 179, 19-26.

Zheng, X., Li, L., Zhao, W., Zhao, W., 2014. Spatial and temporal characteristics of atmospheric $\mathrm{NO}_{2}$ in the Beijing-Tianjin-Hebei region. Ecol. Environ. Sci. 12, 1938-1945 (in Chinese, with English abstract). 